\title{
Diversidade e índices arbóreos em ambientes escolares
}

\author{
Diversity arborial and vegetation indices in environment school \\ Ivan Julio Apolonio Callejas', Luciane Cleonice Durante ${ }^{2}$, Angela Santana de Oliveira ${ }^{3}$, \\ Marta Cristina de Jesus Albuquerque Nogueira ${ }^{4}$ \\ 1, 2, 3,4 Universidade Federal de Mato Grosso, Cuiabá,MT, Brasil
}

\section{Resumo}

Estudos têm demonstrado a importância da diversidade arbórea nos ambientes escolares, tanto em termos de aspecto ambiental, quanto em temos educacionais. No entanto, verifica-se que são escassos os estudos com propostas de um método padrão para avaliar as condições ambientais da arborização existente nas escolas. Constata-se, também, a inexistência de índices arbóreos que possam ser utilizados na definição das áreas a serem destinadas à vegetação nesses ambientes. Assim, neste trabalho objetivou-se realizar um diagnóstico ambiental em três escolas da cidade de Cuiabá-MT através de inventário da vegetação arbórea e estimativa de índices arbóreos, com vistas à definição de índices que possam ser utilizados como referência para a elaboração de projetos paisagísticos em ambientes escolares, bem como no planejamento, conservação e manutenção da vegetação existente nestes espaços. Nos ambientes educacionais pesquisados, notou-se que há equilíbrio entre as espécies nativas e exóticas e frequência relativa elevada de duas ou uma espécie. Os maiores índice de área foliar (IAF) foram determinados em espécies exóticas, como Manguifera Indica L. e Ficus benjamina, bem como em nativas, como a Licania tomentosa (Oiti). Os resultados encontrados sugerem índice de sombreamento arbóreo (ISA) igual ou superior a 40\% e índice de área verde escolar (IAVE) de pelo menos a $12 \mathrm{~m} 2$ /aluno nos ambientes escolares.

Palavras-chave: Vegetação; pátios escolares; índice de sombreamento arbóreo; índice de área verde escolar; índice de área foliar.

\begin{abstract}
Studies have shown the importance of tree diversity in terms of environmental education and for ethical behavior of the students in environmental school. However, there are few studies with a standard proposed method for determining the arboreal vegetation existing inside the schools environmental. There is also a lack of index trees that can be used to design areas for vegetation inside these environments. This study aimed to conduct an environmental assessment in three schools located the Cuiabá city. It was carried out an arboreal inventory and vegetation indexes, in order to evaluate indexes that can be used as references for designing landscape projects for educational environments, as well as to be used in planning, conservation and maintenance of arboreal vegetation existing in these spaces. It was noted in school environment investigated that there was equilibrium between the native and exotic species and it was observed high relative frequency of two species. The largest values of leaf area index was determined in exotic trees such as Manguifera Indica L. and Ficus benjamina, as well as in the native one, like Licania tomentosa (Oiti). The results suggest shading arborization index equal or greater than $40 \%$ and school arboreal vegetation index at least equal to $12 \mathrm{~m} 2$ per student for educational environments.
\end{abstract}

Keywords: Vegetation; School yards; shading arborization index; school vegetation index; Leaf area index. 


\section{INTRODUÇÃO}

A presença da vegetação no ambiente urbano é um fator determinante na melhoria da qualidade de vida. Em se tratando de ambientes escolares, a vegetação arbórea por suas características naturais proporciona muitas vantagens e tem grande influência nas condições de uso dos mesmos, fornecendo sombreamento, influenciando nas condições termo higrométricas e funcionando como obstáculo aos ruídos e aos ventos mais intensos. Além de proporcionar conforto ambiental aos alunos, a vegetação arbórea deve garantir espaços que convidem à prática de atividades pedagógicas e de recreação (FUNDESCOLA, 2002a).

Kowaltowski (2011) recomenda que deve existir uma relação entre os ambientes externo e interno de modo a auxiliar no aprendizado dos alunos em áreas do conhecimento cujas práticas não se realizam de maneira eficaz em salas de aula. Segundo a autora, é necessário que as áreas livres e os pátios externos de uma escola sejam planejados para se obter um projeto paisagístico de fácil manutenção e que propicie aos usuários contato com elementos naturais e vistas humanizadas. Por outro lado, nota-se que a influência da vegetação arbórea vai além das questões de melhoria da qualidade do ambiente. As áreas vegetadas servem como local de interação sociocultural, de realização de atividades recreativas, funcionando inclusive como ambiente para o desenvolvimento do ensino-aprendizagem nas disciplinas de ciências naturais. Conforme relata Elali (2003), as características sócio físicas dos ambientes e as relações entre estes e a criança, oportunizam contato com espaços variados, artificiais e naturais, proporcionando à infância condições plenas de desenvolvimento e gerando consciência de si e do entorno. Ao enfatizar a importância da vegetação, Fedrizzi et al. (2008) destaca que a melhoria da qualidade dos pátios escolares constitui uma importante alternativa no sentido de tornar as escolas mais atrativas e aprazíveis para a comunidade, agregando valores estéticos aos mesmos.

Outro aspecto importante se refere à diversidade arbórea dos pátios. Segundo estudo realizado por Harvey apud Fedrizzi (2008) foi verificada influência positiva do contato com uma maior variedade de plantas sobre a formação ético-ambiental dos alunos. Sob o ponto de vista do ecossistema, a uniformização da paisagem traz como consequência a redução da biodiversidade, elemento importante nos ambientes escolares. A diversidade de espécies é um fator determinante na qualidade ambiental do meio urbano e são escassos os estudos com propostas de um método padrão para tais medidas, inclusive específicos para ambientes escolares (CADORIM et al., 2011).

Além do fator diversidade, outros aspectos podem ser considerados para avaliar a arborização de um ambiente. A partir da análise de alguns estudos (LIMA NETO E SOUZA, 2009; OLIVEIRA et al., 2010), dois índices arbóreos são propostos: Índice de Sombreamento Arbóreo (ISA) e Índice de Densidade Arbórea (IDA). O primeiro se refere ao percentual da área sombreada em relação à área total do sítio estudado, estimado por meio da medida da projeção das copas sobre o solo. O segundo, estima a intensidade de ocupação das árvores em determinado ambiente e se traduz na maior ou menor quantidade de indivíduos arbóreos no mesmo. Conforme destaca Lima Neto e Souza (2009), esses índices constituem-se em indicadores relevantes para estudos de planejamento urbano, qualidade ambiental e arcabouço de modificação da paisagem nas áreas verdes públicas. O ideal é que o ISA e o IDA sejam utilizados em conjunto com a diversidade arbórea, pois estes se complementam, determinando a qualidade da arborização nos ambientes, ou seja, além de quantificar, qualificam o patrimônio das espécies arbóreas presentes no meio urbano. Simões et al. (2001) destaca que em bairros com predomínio de atividades comerciais, o ISA deve ser superior a 30\% e, em residenciais, a $50 \%$. Para o IDA, conforme destaca Lima Neto e Souza (2009), recomenda-se que haja pelo menos 1 indivíduo arbóreo a cada $100 \mathrm{~m}^{2}$. Outra referencia para o Brasil, é a recomendação do Îndice de Áreas Verdes (IAV) mínimo de $15 \mathrm{~m}^{2}$ de áreas verdes destinadas à recreação por habitante (GUZZO, 2006). É importante destacar que na bibliografia consultada não foi encontrado nenhum índice especifico para ambientes escolares.

Outro índice que pode ser utilizado na avaliação da qualidade da arborização é o IAF (Índice de Área Foliar), que constitui um dos principais parâmetros biofísicos e estruturais da vegetação e é definido como a área foliar total por unidade de área do solo $(\mathrm{mm}-2)$. Ele é resultante das respostas ecofisiológicas das plantas às condições químicas, físicas e biológicas do solo e as interdependências destes fatores nos diferentes estágios sucessionais da vegetação (WANDELLI e MARQUES FILHO, 1999). A área foliar além de influenciar as trocas de massa e energia de um ecossistema, participa 
diretamente na interceptação e absorção da luz na copa e se correlaciona diretamente com a qualidade do sombreamento arbóreo (BONAN, 1997). Quanto maior o IAF, maior interceptação da radiação solar pelas folhas, consequentemente maior o sombreamento promovido pelas copas, favorecendo o resfriamento da atmosfera abaixo das mesmas. Desta forma, o IAF constitui um importante parâmetro na avaliação da qualidade da arborização em termos de melhoria das condições bioclimáticas dos ambientes sob sua influência.

$\mathrm{Na}$ tentativa de se produzir um pátio agradável, é muito comum a utilização de espécies exóticas em detrimento às nativas. Cadorim et al.(2011) recomenda que as árvores dos pátios escolares sejam nativas dos biomas brasileiros. Sob o aspecto educacional e da biodiversidade, a presença de espécies nativas corrobora para uma maior percepção do ambiente natural onde o indivíduo se insere. No entanto, quando se analisa essa questão sob outro aspecto, por exemplo, bioclimático, nem sempre a vegetação do bioma local apresenta capacidade de proporcionar condições de conforto ambiental mais adequada. De fato, Callejas et al. (2011), em estudo realizado em ambientes escolares com espécies nativas e exóticas em região de Cerrado, demonstrou que indivíduos arbóreos exóticos com maior índice de área foliar (IAF), foram capazes de promover maior atenuação na temperatura do ar e melhoria na sensação de conforto térmico, bem como elevar a umidade do ar nos ambientes estudados. As condições climáticas do Cerrado impõem modificações fisiológicas às espécies nativas, em especial, baixo índice de área foliar, e consequentemente menor contribuição na atenuação da radiação solar e nas condições termo higrométricas sob suas copas. Nesses casos, faz-se necessário o plantio de árvores nativas e exóticas de tal forma que se possa tirar proveito das espécies arbóreas locais e ao mesmo tempo atender necessidades de conforto ambiental nesses ambientes.

O inventário de identificação e quantificação das espécies arbóreas das escolas e sua classificação quanto à origem e frequência são um importante instrumento para avaliação da diversidade destes ambientes. No entanto, percebe-se que somente estas informações não são capazes de caracterizar a distribuição, a qualidade do sombreamento e a densidade arbórea existente dentro do ambiente escolar. Para isso, outros parâmetros morfológicos são necessários, tais como a localização das espécies no perímetro em estudo, diâmetro das copas, altura das arvores, área e perímetro do local em estudo, dentre outros. Caso se queira aferir a qualidade do sombreamento, bem como melhoria de sensação de conforto térmico proporcionado pela presença da vegetação, deve ser levantado o IAF.

Diante do exposto, é possível observar que alguns trabalhos ora se restringem a analisar a diversidade arbórea do ambiente ou ora se focam em determinar índices arbóreos em espaço urbano. A contribuição deste estudo consiste em mostrar a necessidade de tratar a diversidade em conjunto com os índices arbóreos quando se pretende qualificar a vegetação de um ambiente. Por outro lado, demonstra que quando para promover melhores condições bioclimáticas em ambientes vegetados, existe a necessidade de se trabalhar a qualidade do sombreamento arbóreo, sendo este diretamente relacionado ao Índice de Área Foliar da vegetação em questão.

\section{OBJETIVO}

Este trabalho teve por objetivo realizar um diagnóstico ambiental em três escolas da cidade de Cuiabá-MT por meio de inventário da vegetação arbórea e cálculo dos índices arbóreos, com vistas à definição de índices que sirvam de referência para a elaboração de projetos paisagísticos de ambientes escolares, bem como possam ser utilizados no planejamento, conservação e manutenção da vegetação existente nestes espaços.

\section{MATERIAIS E MÉTODOS}

\section{I LOCALIZAÇÃo dA ÁREA DE ESTUdo}

A pesquisa desenvolveu-se no ambiente urbano da cidade de Cuiabá, Mato Grosso, que juntamente com a cidade vizinha de Várzea Grande constitui um aglomerado urbano com cerca de 900.000 habitantes (IBGE, 2011). Localiza-se na porção Centro-Sul do Estado de Mato Grosso, no limite ocidental dos domínios do Cerrado e próximo à borda leste do Pantanal Mato-grossense. Possui, atu- 
almente, $3538,17 \mathrm{~km}^{2}$, sendo que $254,57 \mathrm{~km}^{2}$ correspondem à área de macrozona urbana e $3.283,60 \mathrm{~km}^{2}$ à área rural. Encontra-se localizada na província geomorfológica denominada Baixada Cuiabana. As altitudes variam de 146 a 259 metros (IPDU, 2009). A cobertura vegetal é constituída por remanescentes de cerrado, cerradão, matas ciliares no entorno dos rios, e por vegetação exótica (Figura 1).

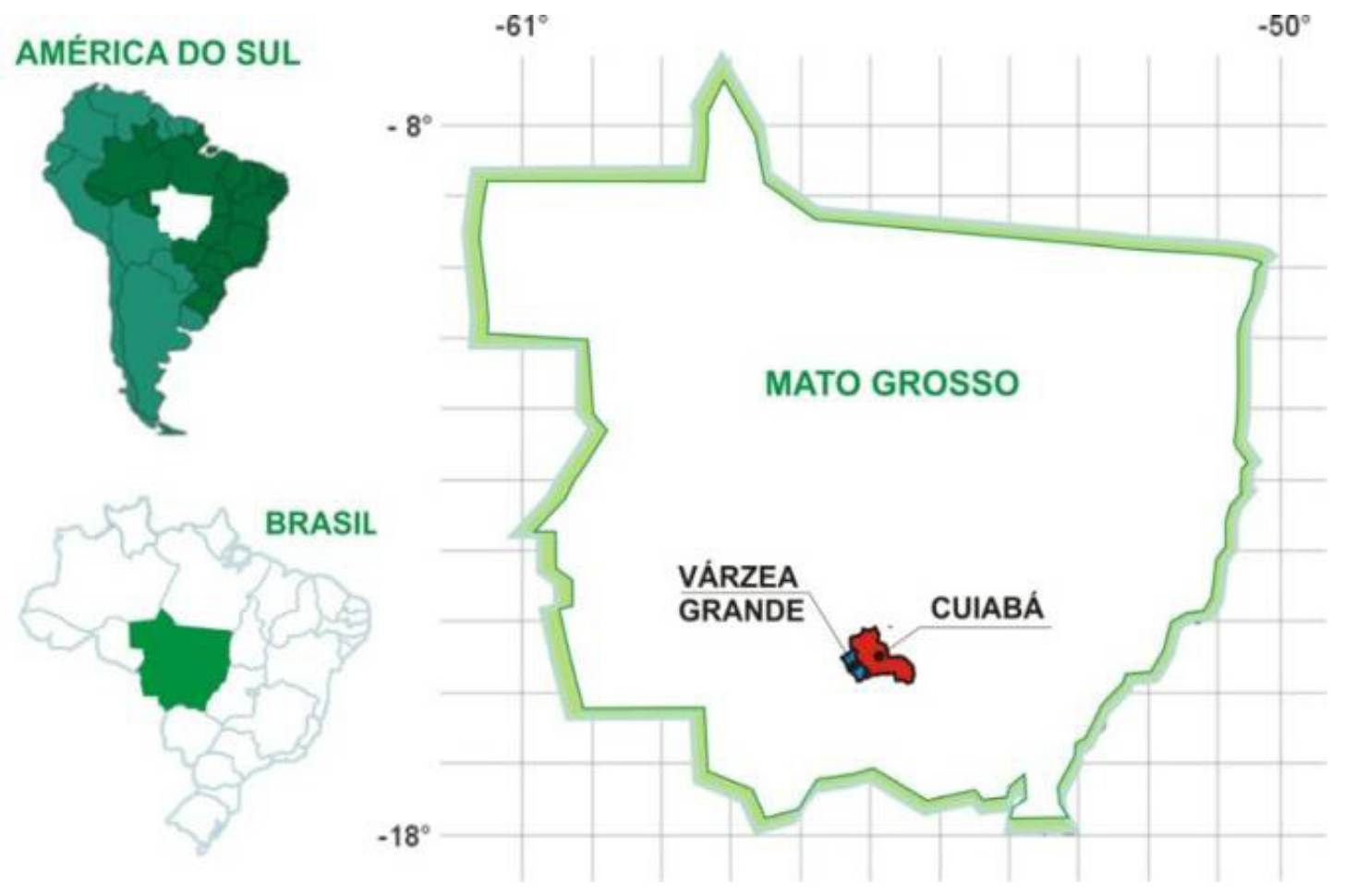

Figura 1. Localização da região do estudo.

O clima dominante é do tipo tropical semi-úmido (classificação $A w$ de Köppen), sendo a sua principal característica a presença constante de temperaturas elevadas, registrando média anual em torno de $25^{\circ}$ a $26^{\circ} \mathrm{C}$, com duas estações bem definidas: uma seca (outono-inverno) e uma chuvosa (primavera-verão) (MAITELLI, 1994). O índice pluviométrico anual varia de 1250 a 1500mm (CAMPELO JUNIOR et al, 1991). Para Duarte (2000), o clima da região é definido por três períodos: uma estação seca e mais fresca no inverno; uma estação de transição seca e mais quente, um pouco antes das chuvas e, uma estação úmida e quente, durante as chuvas do verão.

O universo da pesquisa consistiu da relação de 79 unidades escolares, distribuídas no perímetro urbano e rural do município de Cuiabá, disponibilizadas pela Secretaria de Estado de Educação de Mato Grosso (SEDUC-MT, 2010), das quais foram desconsideradas as unidades localizadas na zona rural e selecionadas para a pesquisa três unidades, de mesmo projeto, com pequenas diferenças de implantação no terreno, de forma a ir de encontro à premissa metodológica de que a principal diferença entre elas é resultante da presença da vegetação arbórea existente dentro do terreno das escolas. $\mathrm{O}$ partido arquitetônico das escolas se caracteriza por blocos horizontais de salas de aula, distribuídos à esquerda e direita em relação a um eixo central, que se inicia no acesso principal da escola. Entre os blocos, formam-se estreitos espaços livres e há um pátio central principal de maior dimensão entre o primeiro e segundo blocos à direita do eixo central. A vegetação arbórea, no entanto, não segue um padrão e encontra-se implanta de forma bem distinta em cada uma das escolas (Figura 3).

As escolas selecionadas localizam-se nas regiões Centro-Leste, Centro-Oeste e Nordeste, denominadas doravante de Escolas 1, 2 e 3, respectivamente (Figura 2). As distâncias relativas entre as Escolas 1-2 e as Escolas 1-3 são respectivamente 4,29 e 5,30 km. As altitudes e as coordenadas geográficas das Escolas 1, 2 e 3 são $197 \mathrm{~m}$ e (-56 $\left.04^{\circ} \mathrm{O},-15^{\circ} 35^{\prime} \mathrm{S}\right)$; $179 \mathrm{~m}$ e $\left(-56^{\circ} 07^{\prime} \mathrm{O},-15^{\circ} 35^{\prime} \mathrm{S}\right)$ e $233 \mathrm{~m}$ e $\left(-53^{\circ} 03^{\prime} \mathrm{O},-15^{\circ} 33^{\prime} \mathrm{S}\right)$, respectivamente (Figura 2). Em termos de número de alunos matriculados em cada escola, verifica-se que as escolas 1, 2 e 3 apresentam respectivamente 1250, 682 e 1820 alunos. 


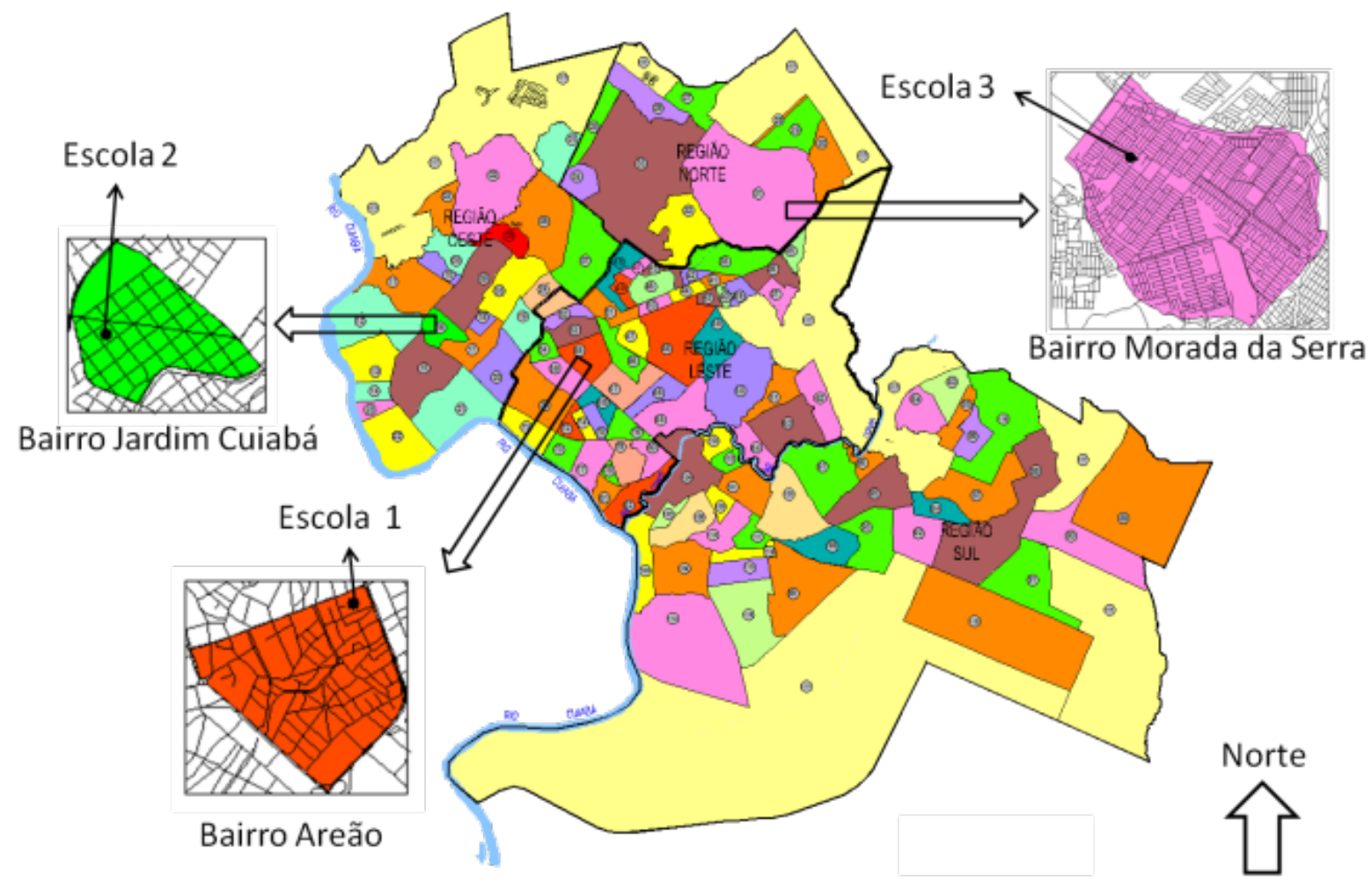

Figura 2. Localização das escolas nos bairros e perímetro urbano de Cuiabá-MT.

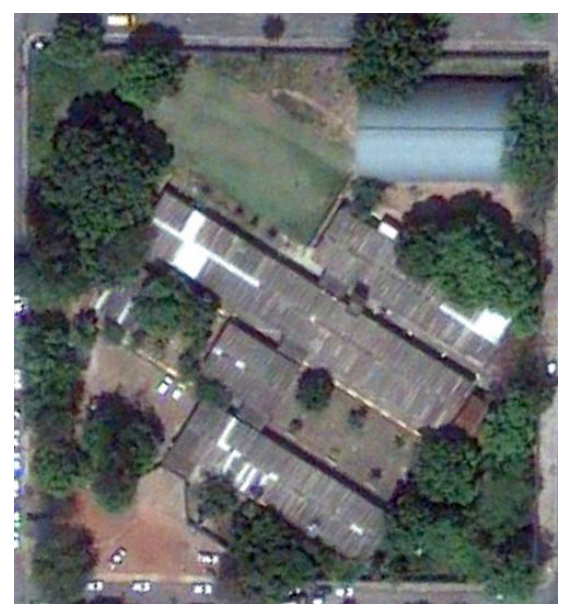

(a)

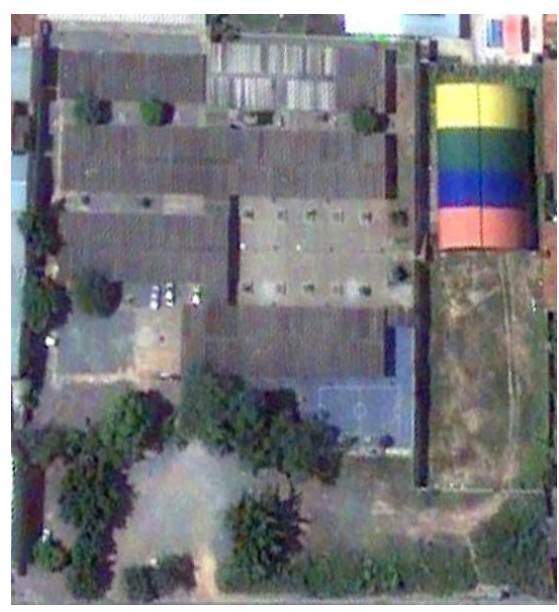

(b)

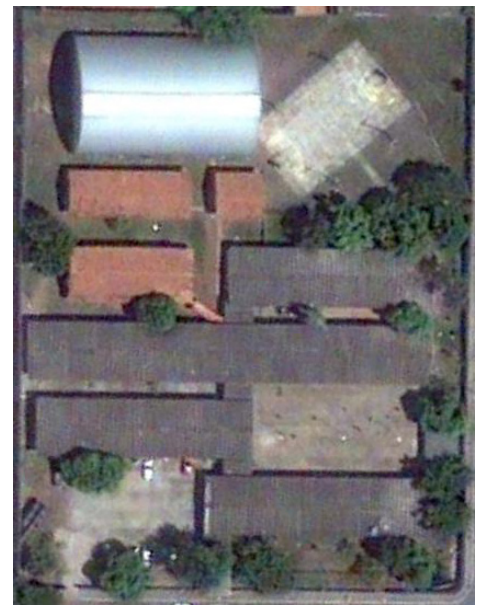

(c)

Figura 3. Vista aérea das espécies arbóreas nas Escolas 1 (a), 2 (b) e 3 (c).

Fonte: Google Earth.

\subsection{IDENTIFICAÇÃO E CARACTERIZAÇÃO DA DIVERSIDADE ARBÓREA}

Como forma de caracterizar a arborização presente dentro de cada escola, realizou-se um inventário onde foram identificadas e contadas as espécies arbóreas existentes em cada sítio. Para tal fim, os seguintes dados foram levantados conforme metodologia proposta por Oliveira et al. (2011): localização das espécies, nomes comuns e científicos, origem, altura das árvores, das copas e fustes e diâmetros das copas. Paralelamente ao inventário proposto, foi realizado levantamento fotográfico e extração de amostras de folhas e flores. A identificação das espécies se deu por meio de bibliografia especializada da flora arbórea brasileira tais como Lorenzi (2002), Lorenzi et al.(2003), Lorenzi et al. (2004) e através do site www.arvores.brasil.nom.br. 


\section{3 Índices de Densidade (IDA), Sombreamento Arbóreo (ISA) e ÍNDICE de Áreas Verdes (IAV)}

Para análise dos índices espaciais da arborização foram localizados dentro dos lotes das escolas, os espécimes arbóreos com altura superior a dois metros juntamente com a medição da projeção de suas copas. Foram estabelecidos em cada árvore dois eixos perpendiculares entre si com a finalidade de auxiliar as medições das projeções das copas, realizada através de trena. Além do levantamento in loco, utilizou-se de imagens de satélites extraídas do programa Google Earth para complementar as medidas obtidas em conjunto com software de desenho.

De posse destas informações, os seguintes índices propostos por Simões et al. (2001) foram utilizados: Îndice de Densidade Arbóreo (IDA) e Índice de Sombreamento Arbóreo (ISA). O primeiro índice consiste no número de árvores existentes em cada $100 \mathrm{~m}^{2}$. Este cálculo revela se a área em estudo apresenta uma deficiência ou abundância de vegetação arbórea. É determinado pela seguinte equação:

$$
\text { Equação } 1 \quad \mathrm{IDA}=\left[\frac{\mathrm{N}_{\text {árvores }}}{\text { Área }_{\text {Total }}\left(\mathrm{m}^{2}\right)}\right] \times 100
$$

O segundo (ISA) se refere ao percentual de área sombreada em relação à área total. Por meio dele obtém-se o potencial de sombra resultante da soma das áreas de projeção das copas. Esse índice é definido pela seguinte expressão:

$$
\text { Equação } 2 \text { ISA }=\left[\frac{\text { Área }_{\text {sombreada }}\left(\mathrm{m}^{2}\right)}{\text { Área } \text { Total }^{2}\left(\mathrm{~m}^{2}\right)}\right] \times 100
$$

O primeiro índice foi confrontado com o valor mínimo proposto por Lima Neto e Souza (2009) que recomenda pelo menos um (1) indivíduo arbóreo a cada $100 \mathrm{~m} 2$. Já o segundo, serviu de referencia para checar as recomendações de Simões et al. (2001) para bairros com predomínio de atividades comerciais e residenciais.

Baseado no Índice de Áreas Verdes propõe-se neste trabalho uma adaptação do mesmo ao universo escolar, substituindo a variável habitante pela média dos alunos matriculados no período matutino, vespertino ou noturno. Assim, o Índice de Área Verde Escolar (IAVE) pode ser definido da seguinte forma:

$$
\text { Equação } 3 \quad \mathrm{AVE}=\left[\frac{\text { Área }_{\text {sombreada }}\left(\mathrm{m}^{2}\right)}{\text { Alunos matriculados periodo }}\right]
$$

\section{4 ÍNDICES DE ÁREA FOLIAR}

O IAF foi medido por meio do equipamento Ceptômetro LP-80 AccuPAR, Decagron Devices. O método consiste da medição da radiação solar global seguida de quatro medições à sombra da copa da unidade arbórea (Figura 4a e 4b), após o que o se lê diretamente o IAF.

Com a finalidade de comparar os ambientes escolares, calculou-se o IAF médio da arborização presente nos sítios escolares.

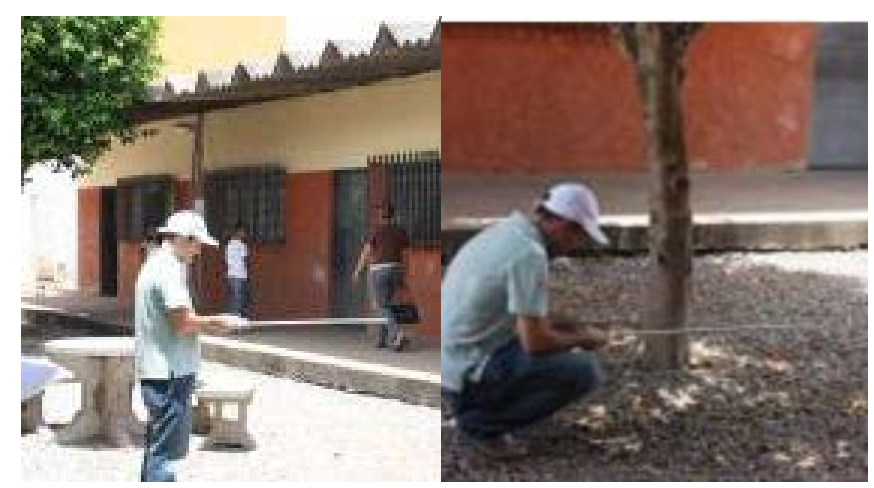

(a)

(b)

Figura 4. (a) Medição da radiação solar global incidente e (b) sob a copa da árvore. 


\section{RESULTADOS E DISCUSSÃO}

\section{I DiverSIDADE ARBóREA NAS ESCOLAS}

$\mathrm{Na}$ Escola 1 foram contabilizados 30 indivíduos e 11 espécies arbóreas, sendo destas, 6 exóticas e 5 nativas. As duas espécies mais frequentes foram Ficus benjamina (Fícus) e Albizia lebbeck (L.) Benth( Língua de Sogra) as quais correspondem a 37\% e 17\% das espécies existentes, respectivamente. Para a Escola 2 foram registrados 93 indivíduos e 26 espécies, das quais 13 são consideradas exóticas e 13 nativas. A espécie com maior número de indivíduos foi a Manguifera Indica L. (Mangueira) com $37 \%$ de freqüência seguida da Acrocomia aculeata (Bocaiúva) com 12\%. Na quantificação dos espécimes arbóreos da Escola 3 registrou-se 29 indivíduos e 10 espécies divididas em cinco nativas e cinco exóticas. As maiores frequências foram da Licania tomentosa (Oiti) com $28 \%$ e Peltophorum dubium (Spreng.) Taub.(Canafístula) com 21\%.

Ao se comparar a frequência relativa de cada espécie presente na Escola 1, constata-se que os indivíduos da espécie Ficus benjamina (Fícus) e Albizia lebbeck (L.) Benth (Língua de Sogra) ultrapassaram a taxa de frequência relativa sugerida entre 10 a $15 \%$ por Grey e Deneke apud Lima Neto e Souza (2009) para ambientes urbanos. Outro fato percebido é que de todas as árvores presentes, as mais frequentes são exóticas com mais de um indivíduo por espécie, enquanto as nativas são menos frequentes com apenas um indivíduo por espécie (Tabela 1).

A Escola 2 tem como espécie dominante a Manguifera Indica L. (Mangueira) com elevada taxa de frequência. Esta espécie, apesar de ser uma espécie exótica, adaptou-se ao clima local e está bastante presente na paisagem urbana da cidade de Cuiabá. Por este motivo, faz parte da história e da cultura regional. Outra espécie que se destacou em número de indivíduos foi a Acrocomia aculeata (Bocaiúva), de origem nativa. No entanto, esta palmeira apresenta baixo índice de área foliar (IAF), não contribuindo de forma significativa na atenuação da radiação solar direta e na melhoria da sensação de conforto térmico. Embora na Escola 2 apenas duas espécies representem cerca de 50\% dos indivíduos arbóreos (Tabela 2), nela verificou-se maior quantidade de espécies e a melhor distribuição espacial das mesmas no ambiente escolar. Outro fato importante é a presença de variedade de árvores frutíferas que, além de auxiliarem no processo de ensino de ciências da natureza, evidenciam a importância das frutas no contexto alimentar dos alunos.

Tabela 1. Espécies arbóreas presentes na Escola 1.

\begin{tabular}{|c|c|c|c|c|c|c|}
\hline № & Espécie/Familia & $\begin{array}{c}\text { Nome } \\
\text { Popular }\end{array}$ & Origem & $\begin{array}{c}\text { IAF } \\
\left(\mathrm{m}^{2} \mathrm{~m}^{-2}\right)\end{array}$ & Quant. & $\begin{array}{l}\text { F.R. } \\
(\%)\end{array}$ \\
\hline 1 & Ficus benjamina/Moraceas & Ficus & $\mathrm{E}$ & 5,34 & 11 & 37 \\
\hline 2 & $\begin{array}{c}\text { Albizia lebbeck (L.) Benth/Loguminosae- } \\
\text { mimosoideae }\end{array}$ & $\begin{array}{c}\text { Lingua de } \\
\text { sogra }\end{array}$ & $\mathrm{E}$ & 4,39 & 5 & 17 \\
\hline & Persea americana/Lauraceas & Abacateiro & $E$ & 4,42 & 3 & 10 \\
\hline 4 & Malvighia marginata/Malvighiacoae & Acerola & $E$ & 4,35 & 3 & 10 \\
\hline 5. & Roystonea regia/Palmae & $\begin{array}{l}\text { Palmeira } \\
\text { Imperial }\end{array}$ & $\mathrm{E}$ & (a) & 2 & 7 \\
\hline 6 & Hibiscus riliacrus L./Malvacrae & $\begin{array}{c}\text { Algodão do } \\
\text { brejo }\end{array}$ & $\mathrm{N}$ & 4,79 & 1 & 3 \\
\hline 7 & Acrocomia aculeata /Palmae & Bocaiúva & $\mathrm{N}$ & (a) & 1 & 3 \\
\hline 8 & Muntingia calabura L. / Tiliacease & $\begin{array}{l}\text { Cereja do } \\
\text { Pará }\end{array}$ & $\mathrm{N}$ & 5,75 & 1 & 3 \\
\hline$\frac{8}{2}$ & Manguifera Indioa L. / Anacardiacea & Mangueira & $\mathrm{E}$ & 6,67 & 1 & 3 \\
\hline 10 & Licania tomentosa/Chrysobalanacoal & Oiti & $\mathrm{N}$ & 7,67 & 1 & 3 \\
\hline 11 & $\begin{array}{l}\text { Clitoria fairchildiana } \\
\text { Howard/Leguminosae-papilionoideae }\end{array}$ & Sombreiro & $\mathrm{N}$ & 5,31 & 1 & 3 \\
\hline \multicolumn{4}{|c|}{ Total } & 5,41 & 30 & 100 \\
\hline
\end{tabular}

(a) Índice não avaliado 
Tabela 2. Espécies arbóreas presentes na Escola 2.

\begin{tabular}{|c|c|c|c|c|c|c|}
\hline № & Espécie/Família & $\begin{array}{c}\text { Nome } \\
\text { Popular }\end{array}$ & Origem & $\begin{array}{c}\text { IAF } \\
\left(\mathrm{m}^{2} \mathrm{~m}^{-2}\right)\end{array}$ & Quant. & $\begin{array}{l}\text { F.R. } \\
(\%)\end{array}$ \\
\hline 1 & Manguifera Indica L.(Anacardiaceae) & Mangueira & $\mathrm{E}$ & 7,60 & 34 & 37 \\
\hline 2 & Acrocomia aculeata(Palmae) & Bocaiúva & $\mathrm{N}$ & 4,94 & 11 & 12 \\
\hline 3 & Eucaliptus spp(Myrraceae) & $\begin{array}{l}\text { Eucalipto } \\
\text { Maminha de }\end{array}$ & $\mathrm{E}$ & 5,99 & 4 & 4 \\
\hline 4 & $\begin{array}{l}\text { Fagara hassleriana(Meliaceae) } \\
\text { Bauhinia monandra Kurz(Leguminosae- }\end{array}$ & Porca & E & (a) & 4 & 4 \\
\hline 5 & caesaipinioideae) & Pata de vaca & $\mathrm{E}$ & 4,35 & 4 & 4 \\
\hline 6 & Anadenthera falcata(Fabaceae) & Angico & $\mathrm{N}$ & (a) & 3 & 3 \\
\hline 7 & Anacardium occidentale (Anacardiaceae) & Cajueiro & $\mathrm{N}$ & 6,56 & 3 & 3 \\
\hline 8 & Genipa americana(Rubiaceae) & Jenipapo & $\mathrm{N}$ & 7,45 & 3 & 3 \\
\hline 9 & Persea americana(Lauraceae) & Abacateiro & $\mathrm{E}$ & (a) & 2 & 2 \\
\hline 10 & Ficus benjamina(Moraceae) & Ficus & $\mathrm{E}$ & 7,56 & 2 & 2 \\
\hline 11 & Delonix regia(Fabaceae) & Flamboyant & E & 4,29 & 2 & 2 \\
\hline 12 & Psidium guajava L.(Myraceae) & Goiabeira & $\mathrm{N}$ & 4,61 & 2 & 2 \\
\hline 13 & $\begin{array}{c}\text { Albizia lebbeck (L.) Benth (Leguminosae- } \\
\text { mimosoideae) }\end{array}$ & $\begin{array}{l}\text { Lingua de } \\
\text { sogra }\end{array}$ & $\mathrm{E}$ & (a) & 2 & 2 \\
\hline 14 & Licania tomentosa(Chrysobalanaceae) & Oiti & $\mathrm{N}$ & 6,96 & 2 & 2 \\
\hline 15 & Pinanga patula(Palmae) & Palmeira & $\mathrm{N}$ & 5,95 & 2 & 2 \\
\hline 16 & $\begin{array}{c}\text { Caesalpinia echinata Lam.(Leguminosae- } \\
\text { caesalpinioideae) } \\
\text { Tabebuia Impetiginosa (Man.) }\end{array}$ & Pau-brasil & $\mathrm{N}$ & (a) & 2 & 2 \\
\hline 17 & (Bignoniaceae) & Ipê Roxo & $\mathrm{E}$ & 6,03 & 2 & 2 \\
\hline 18 & Scheelea phalerata Mart.(Palmae) & Acuri & $\mathrm{N}$ & 5,44 & 1 & 1 \\
\hline 19 & Rubus rostfolus(Rosaceae) & Amora & $\mathrm{N}$ & 5,05 & 1 & 1 \\
\hline 20 & Annona SR(Annonaceae) & Ata & $\mathrm{E}$ & (a) & 1 & 1 \\
\hline 21 & (Citrus $x$ limon) (Rutaceae) & Limoeiro & E & 6,58 & 1 & 1 \\
\hline 22 & Citrus reticulata(Rutaceae) & Mexerica & $\mathrm{E}$ & (a) & 1 & 1 \\
\hline 23 & $\begin{array}{c}\text { Datura Stramonium(Solanaceae) } \\
\text { Clitoria fairchildiana }\end{array}$ & $\begin{array}{l}\text { Orelha de } \\
\text { macaco }\end{array}$ & $\mathrm{N}$ & (a) & 1 & 1 \\
\hline 24 & Howard (Leguminosae-papilionoideae) & Sombreiro & $\mathrm{N}$ & 7,15 & 1 & 1 \\
\hline 25 & Tamarindus indica L.(Leguminosae) & Tamarindo & E & 7,14 & 1 & 1 \\
\hline 26 & Vitex Cymosa(Lecythidaceae) & Tarumã & $\mathrm{N}$ & (a) & 1 & 1 \\
\hline \multicolumn{4}{|c|}{ Total } & 6,10 & 93 & 100 \\
\hline
\end{tabular}

(a) Índice não avaliado

Tabela 3. Espécies arbóreas presentes na Escola 3.

\begin{tabular}{|c|c|c|c|c|c|c|}
\hline No & Espécie/Familia & $\begin{array}{l}\text { Nome } \\
\text { Popular }\end{array}$ & Origem & $\begin{array}{c}\text { IAF } \\
\left(\mathrm{m}^{2} \mathrm{~m}^{-2}\right)\end{array}$ & Quant. & $\begin{array}{l}\text { F.R. } \\
(\%)\end{array}$ \\
\hline 1 & $\begin{array}{c}\text { Licania tomentosa/Chrysobalanaceas } \\
\text { Peltophorum dubium (Spreng.) }\end{array}$ & Oiti & $\mathrm{N}$ & 6,85 & 8 & 28 \\
\hline 2 & Taub./Leguminosae-caesalpinoideae & Canafistula & $\mathrm{N}$ & 4,35 & 6 & 21 \\
\hline 3 & Psidium guajava L./Myrtaceae & Goiabeira & $\mathrm{N}$ & 4,95 & 3 & 10 \\
\hline 4 & $\begin{array}{l}\text { (Cimus } x \text { limon)/Rutaceas } \\
\text { Senna siamea (Lam)/Lequminosas- }\end{array}$ & $\begin{array}{l}\text { Limoeiro } \\
\text { Cassia do }\end{array}$ & $\mathrm{E}$ & 6,39 & 3 & 10 \\
\hline 5 & caesalpinoideas & $\begin{array}{l}\text { Sião } \\
\text { Chuva de }\end{array}$ & $\mathrm{E}$ & 6,19 & 2 & 7 \\
\hline 6 & $\begin{array}{c}\text { Cassia fermuginea Schrad ex DC./Fabaceae } \\
\text { Tabebuia Impetiginosa }\end{array}$ & ouro & $\mathrm{N}$ & 4,6 & 2 & 7 \\
\hline 7 & (Mant.)/Bignoniaceas & Ipê Roxo & $\mathrm{E}$ & 5,03 & 2 & 7 \\
\hline 8 & Persea americana/Lauraceae & Abacateiro & $\mathrm{E}$ & 2,78 & 1 & 3 \\
\hline 9 & Malpighia marginata/Malpighiaceas & Acerola & $\mathrm{E}$ & (a) & 1 & 3 \\
\hline 10 & Anacardium occidentale/Anacardiaceas & Cajueiro & $\mathrm{N}$ & 2,47 & 1 & 3 \\
\hline \multicolumn{4}{|c|}{ Total } & $\overline{4,85}$ & 29 & 100 \\
\hline
\end{tabular}

(a) Índice não avaliado 


\section{2 ÍNDICES ESPACIAIS DA ARBORIZAÇÃO NAS ESCOLAS}

$\mathrm{Na}$ análise dos índices espaciais, a Escola 2 apresentou o maior índice de sombreamento arbóreo com ISA de aproximadamente 33,40\%. Dessa maneira, constata-se que o índice registrado se encontra acima de $30 \%$, padrão recomendado para áreas onde predominam as atividades comerciais, e abaixo de $50 \%$, padrão para áreas de uso predominantemente residencial. Pode se afirmar que as mangueiras presentes no terreno desta escola respondem pela maior parte da área sombreada. Isso acontece não só pelo fato de a espécie apresentar um maior número de indivíduos, mas também por se caracterizar por uma grande e densa copa, com elevado Índice de Área Foliar (CALLEJAS et al., 2011). Em relação ao Índice de Densidade Arbórea, a escola registrou IDA de 0,80 árvores para cada $100 \mathrm{~m}^{2}$, valor considerado bom quando comparado as demais escolas, mas abaixo da recomendação mínima de um (1) indivíduo arbóreo para cada $100 \mathrm{~m}^{2}$. Assim como os demais índices, o Índice de Área Verde Escolar foi o que apresentou melhor relação entre as escolas estudadas, 11,40m2/aluno, no entanto, inferior ao valor de referência no Brasil de $15 \mathrm{~m} 2 /$ habitante (Tabela 4).

Nas Escolas 1 e 3 foram registrados Índice de Sombreamento Arbóreo de 9,26 e 12,35\%, muito abaixo do recomendado para áreas comerciais e residenciais. Resultado semelhante foi encontrado para o Índice de Densidade Arbórea, 0,24 e 0,26 individuo arbóreo por 100m2 para as Escolas 1 e 3, respectivamente. Estes valores são muito inferiores aos recomendados por Lima Neto e Souza (2009). O mesmo aconteceu para o Índice de Área Verde Escolar proposto, com valores de 2,72 e 2,30m2/ aluno. Os baixos índices encontrados podem ser atribuídos em parte às características da vegetação presentes em cada sítio, mas principalmente devido ao menor número de espécimes arbóreos nos mesmos (Tabela 4).

A qualidade do sombreamento presente em cada escola foi quantificada através do Índice de Área Foliar (IAF). As árvores presentes na Escola 2 foram as que apresentaram maior índice de área foliar com 6,09 m2 m-2. Os maiores índices foram avaliados nos espécimes de Manguifera Indica L. (Mangueira) e Ficus benjamina (Moraceae) (Fícus), enquanto os menores foram avaliados no Delonix regia (Fabaceae) (Flamboyant) e na Kurz (Leguminosae-caesalpinioideae) (Pata de Vaca). Na Escola 1, a média do IAF foi de $5,37 \mathrm{~m} 2 \mathrm{~m}-2$, sendo que os maiores índices foram avaliados no Manguifera Indica L./Anacardiaceae (Mangueira) e na Licania tomentosa/Chrysobalanaceae (Oiti) e os menores na Malpighia emarginata/Malpighiaceae (Acerola) e Albizia lebbeck (L.) Benth/Leguminosae-mimosoideae (Língua de sogra). Na escola 3, a média do IAF foi de 4,85 m2 m-2 e os maiores índices foram determinados nos espécimes do Licania tomentosa/Chrysobalanaceae (Oiti) e (Citrus X limon)/Rutaceae (Limoeiro), enquanto os menores foram no Anacardium occidentale/Anacardiaceae (Cajueiro) e Persea americana/Lauraceae (Abacateiro). Em estudo realizado nestas mesmas escolas, Callejas et al. (2011) demonstrou que existe relação direta entre a melhoria das condições de conforto térmico, diminuição da temperatura do ar e elevação da umidade com o Índice de Área Foliar. As medições realizadas demonstraram que à medida que o IAF se elevou, melhores foram as condições temperatura, umidade e de conforto térmico registradas sob as copas das árvores. Assim, a Escola 2, além de registrar os melhores índices espaciais, apresentou as melhores condições termo higrométricas e de conforto térmico sob as copas.

Tabela 4. Índices arbóreos e IAF médio das arborizações presentes nas Escolas 1, 2 e 3.

\begin{tabular}{|c|c|c|c|c|}
\hline Escolas & ISA ( $\%)$ & IDA (Individuo $/ 100 \mathrm{~m}^{2}$ ) & IAVE ( $\mathrm{m}^{2} /$ aluno) & $\operatorname{IAF}_{\mathrm{meds}}\left(\mathrm{m}^{2} \mathrm{~m}^{-2}\right)$ \\
\hline Escola 1 & 9,26 & 0,24 & 2,72 & 5,37 \\
\hline Escola 2 & 33,40 & 0,80 & 11,40 & 6,09 \\
\hline Escola 3 & 12,35 & 0,26 & 2,30 & 4,85 \\
\hline
\end{tabular}

Além dos baixos índices de sombreamento e densidade, percebe-se que não há uma distribuição uniforme dos espécimes arbóreos nos sítios. Esta situação é verificada inclusive na Escola 2, cujo ISA e IDA se apresentam muito próximos aos valores recomendados por Simões et al. (2001). Outro fator importante que deve ser destacado é a ausência e deficiência de árvores nos espaços destinados 
às interações sociais e às atividades recreativas dos alunos e funcionários. Em relação aos pátios centrais, apenas na Escola 2 há indivíduos arbóreos com características de médio porte, o que promove o sombreamento dos mesmos e a convivência social neste ambiente. No pátio da Escola 1 existem árvores de pequeno porte, ainda em fase de crescimento, e por isso com baixa capacidade de sombreamento. O pátio central da Escola 3 é desprovido de indivíduos arbóreos. Aliada à esta deficiência de obstáculos à incidência da radiação solar direta, grandes superfícies de concreto tornam os pátios centrais armazenadores de energia e emissores de radiação de ondas longas, o que piora a sensação de desconforto térmico nesses ambientes. Por este motivo, há preferência por parte dos alunos de utilizar os espaços cobertos do eixo principal dos edifícios em detrimento das áreas ao ar livre. Isso acontece com mais frequência nas escolas em que há menor número de indivíduos arbóreos em seus pátios centrais. Este comportamento foi verificado na Escola 2 durante um ensaio da banda escolar (fanfarra) onde os alunos abrigaram-se sob as copas de grandes mangueiras em local que nem sequer havia algum tipo de pavimentação que facilitasse a locomoção. Este fato demonstra a capacidade que uma boa arborização tem em fornecer um ambiente confortável para atividades e interações sociais.

Outro aspecto importante a ser comentado é que grande parte dos indivíduos arbóreos se localizam em espaços periféricos aos edifícios escolares, muitas vezes não destinados à convivência e recreação, frequentemente inutilizados devido à presença de mato e entulho, situação que se sobrepõe ao caráter atrativo das áreas sombreadas sob as copas das árvores. Por outro lado, quando o objetivo é promover a interação e o conforto térmico, é conveniente que estas estejam localizadas nas áreas externas de convivência e de maior permanência (pátio central, interblocos, dentre outros). É importante destacar que a baixa densidade e desigual distribuição das espécies arbóreas avaliadas nas escolas pesquisadas trazem como consequência a diminuição da capacidade da flora arbórea em reduzir ruídos provenientes do sistema viário local, incidência de radiação solar e ventos fortes, em aumentar a umidade por evapotranspiração e ainda em fornecer um ambiente de aprendizado em contato com a natureza.

\subsection{Proposta de ISA e IAVE para as Escolas}

Com base na recomendação para o índice de densidade arbóreo mínimo de um (1) individuo para cada $100 \mathrm{~m}^{2}$, calculou-se qual seria o ISA mínimo recomendado para os ambientes escolares em estudo. Para isso, buscou-se quantos indivíduos arbóreos seriam necessários para atingir o IDA mínimo recomendado por Simões et al. (2001). Os resultados demonstraram que 123, 116, 113 unidades arbóreas seriam necessárias para adequar a Escola 1, 2 e 3, respectivamente, ao padrão proposto pelo autor. Em seguida, esses valores foram multiplicados pela área média da projeção da copa existente em cada uma das escolas, possibilitando, dessa forma, obter a área da projeção das copas recomendadas para cada uma das escolas. De posse da área de projeção das copas, recalculou-se os valores de ISA e IAVE que atendem o critério estabelecido de um indivíduo a cada $100 \mathrm{~m} 2$. Os resultados podem ser visualizados na Tabela 5. Com o objetivo de estabelecer parâmetros para ambientes escolares, calculou-se a média dos ISA e IAVE encontrados, chegando-se a valores de 42,58\% e 11,45m2/aluno. Observa-se que os índices da Escola 2 são os que mais se aproximam dos parâmetros encontrados, reforçando os resultados encontrados no estudo realizado nos mesmos ambientes escolares por Callejas et al. (2011) que demonstrou que as mangueiras presentes na Escola 2 foram as mais eficientes em atenuar a temperatura e aumentar umidade do ar, bem como promover melhores condições de conforto térmico sob suas copas, quando comparado com algumas espécies arbóreas presentes nas outras duas escolas (Oiti e Fícus). No estudo deste autor, ao se comparar a Escola 2, que apresenta ISA de 33,4\% com as demais, pode ser percebido melhoria das condições ambientais provocada pela presença da vegetação arbórea naquele sítio educacional.

Assim sendo, baseado nos resultados encontrados nas três escolas estudadas, sugere-se como valor referencial para elaboração de projetos paisagísticos, bem como para fins de planejamento, conservação e manutenção da vegetação arbórea em ambientes escolares valores de ISA superiores a $40 \%$ e IAVE de pelo menos $12 \mathrm{~m} 2$ /aluno. Para atender a esse índice proposto, sugere-se o plantio de árvores nativas que apresentem grande potencial de sombreamento (elevado IAF), lembrado que estas não devem ser tóxicas, em virtude da possibilidade de contato por parte dos alunos. Deverão ser distribuídas nas áreas de convivência e de maior permanência dos alunos, com vistas a atender os níveis de conforto ambiental destas áreas (térmico e acústico). Sugere-se que os pátios centrais apresentem espécies arbóreas visto que neles se desenvolvem muitas atividades de convivência e recreação. 
Tabela 5. Índices arbóreos estimados assumindo IDA igual a 1,0 indivíduo por 100m2.

\begin{tabular}{|c|c|c|c|c|}
\hline Escolas & $\frac{\mathrm{DA}}{\text { (Individuo } / 100 \mathrm{~m}^{2} \text { ) }}$ & $\begin{array}{c}\text { Quantidade de } \\
\text { unidades } \\
\text { arbóreas }\end{array}$ & $\begin{array}{c}\text { ISA (\%) } \\
\text { Recomendado }\end{array}$ & $\begin{array}{c}\text { IAVE } \\
\left(\mathrm{m}^{2} / \text { aluno }\right)\end{array}$ \\
\hline Escola 1 & 1 & 123 & 37,87 & 11,15 \\
\hline Escola 2 & 1 & 116 & 41,69 & 14,19 \\
\hline Escola 3 & 1 & 113 & 48,19 & 9,00 \\
\hline \multicolumn{3}{|c|}{ Média } & 42,58 & 11,45 \\
\hline
\end{tabular}

\section{CONCLUSÕES}

Este trabalho surgiu da necessidade de definir parâmetros de referência que possam ser utilizados pelos profissionais de engenharia e arquitetura durante as etapas de desenvolvimento de um projeto, em especial no programa de necessidades dos ambientes escolares. Durante esta etapa, são definidos os espaços arquitetônicos de acordo com o conjunto de atividades sociais e funcionais para o qual a edificação se destina. É nesse momento que o profissional se depara com a necessidade de definir os tipos de arborização a serem implantadas nos ambientes escolares para fins de atividades pedagógicas, de recreação e paisagísticas. Os resultados obtidos subsidiam a tomada de decisões relativas à localização, quantidade e qualidade da arborização especificada, bem como, orienta no sentido das espécies indicadas para plantio.

Nos ambientes estudados, verificou-se a ocorrência de equilíbrio entre as espécies nativas e exóticas e a existência de frequência relativa elevada normalmente de duas ou uma espécie arbórea. Os maiores IAF foram determinados em espécies arbóreas exóticas, como Manguifera Indica L.(Mangueira) e Ficus benjamina(Moraceae) (Fícus), bem como nas nativas, como o Licania tomentosa(Chrysobalanaceae) (Oiti). A Escola 2 apresentou os melhores índices dentre as estudadas, sendo esta utilizada como referência para a definição dos índices sugeridos neste trabalho. Os resultados indicam que o ISA, o IDA e o IAV guardam certa relação entre si, visto que ao se calcular o ISA e o IAV a partir do IDA igual a 1,0, praticamente encontrou-se os valores ideais sugeridos na literatura para aqueles índices, como pode ser observado na Tabela 5, onde se sugere para ambientes escolares ISA superiores a $40 \%$ e IAVE de pelo menos $12 \mathrm{~m} 2$ /aluno. É importante frisar que estes valores são apenas parâmetros iniciais e que precisam ser mais elaborados a partir do aprofundamento de pesquisas sob o tema. Destaca-se também que não se pretende neste trabalho estabelecer limites rígidos e universais para os índices de ISA e IAVE, visto que cada ambiente possui as suas próprias características, que precisam ser atendidas individualmente. O que se objetiva é fornecer parâmetros que possam guiar os profissionais que desenvolvem projetos escolares, bem como aqueles que trabalham nestes estabelecimentos com vista a poder planejar, conservar e fazer a manutenção nas áreas vegetadas existente nos sítios escolares.

\section{AGRADECIMENTOS}

Agradecemos à Fundação de Amparo à Pesquisa de Mato Grosso - FAPEMAT pelo suporte financeiro a esta pesquisa.

\section{REFERÊNCIAS}

BONAN, G. B. Effects of land use on the climate of the United States. Climatic Change, v.37, p.449-486, 1997.

BRASIL. Ministério da Educação. Fundo de Fortalecimento da Escola - FUNDESCOLA. Espaços Educa- 
tivos. Ensino fundamental. Subsídios para Elaboração de Projetos e Adequação de Edificações Escolares: Cadernos Técnicos. Brasília, 2002. (Cadernos Técnicos 4).

CADORIN, D. A., HASSE, I., SILVA, L. M., BETT, C. F. Características da flora arbórea de quatro escolas de Pato Branco-PR. Soc. Bras. de Arborização Urbana REVSBAU, Piracicaba - SP, v.6, n.2, p.104-124, 2011.

CALlejAS, I. J. A., DURANTE, L. C., NOGUEIRA, M. C. de J. A., NOGUEIRA, J. de S., CAMPOS, A. C. S. Estudo do sombreamento arbóreo, atenuação da radiação solar e microclima dos pátios escolares: elementos para se pensar a sustentabilidade urbana. In: IV Encontro Latino-americano sobre Edificações e Comunidades Sustentáveis, 2011, Vitória. Anais... Vitória, 2011.

CAMPELO JÚNIOR, J. H., PRIANTE FILHO, N., CASEIRO, F. T. Caracterização macroclimática de Cuiabá. III In: Encontro Nacional de Estudos sobre o Meio Ambiente. 1991, Londrina. Anais... 1991. Londrina, 1991.

ELALI, G. O ambiente na escola: uma discussão sobre a relação escola-natureza em educação infantil. Estudos de Psicologia, v. 8, n. 2, p.309-319, 2003.

FEDRIZZI, B., TOMASINI, S. L. V., CARDOSO, L. M. A vegetação no pátio escolar: um estudo para a realidade de Porto Alegre-RS. Soc. Bras. de Arborização Urbana. Disponível em < http://www.sbau.org.br $>$. Acesso em: 10 ago. 2011.

GUZZO, Perci. Cadastro Municipal de Espaços Livres Urbanos de Ribeirão Preto (SP): Acesso Público, Índices e Base para Novos Instrumentos e Mecanismos de Gestão. Revista da Sociedade Brasileira de Arborização Urbana, v1, n 1, 2006.

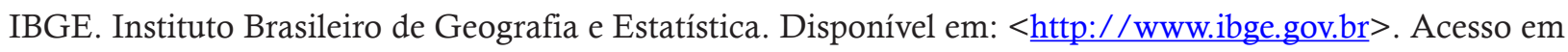
abr. 2011.

IPDU. Instituto de Pesquisas e Desenvolvimento Urbano. Perfil Socioeconômico de Cuiabá, V. IV. Cuiabá: Central de Texto, 2009.

KOWALTOWSKI, D. K. Arquitetura Escolar. 1. ed. Cidade: Oficina de textos, 2011.

LIMA NETO, E. M. \& SOUZA, R. M. Índices de densidade e sombreamento arbóreo em áreas verdes públicas de Aracaju, Sergipe. Soc. Bras. de Arborização Urbana REVSBAU, Piracicaba - SP, v.4, n.4, p.47-62, 2009.

LORENZI, H. Árvores exóticas no Brasil: madeireiras, ornamentais e aromáticas. Nova Odessa: Instituto Plantarum de Estudos da Flora, 2003.

LORENZI, H. Palmeiras brasileiras e exóticas cultivadas. Nova Odessa, SP: Instituto Plantarum, 2004.

LORENZI, H. Árvores brasileiras: manual de identificação e cultivo de plantas arbóreas do Brasil, 4.ed. Nova Odessa, SP: Instituto Plantarum, 2002.

MAITELLI, G. T. Uma Abordagem Tridimensional de Clima Urbano em Área Tropical Continental. O Exemplo de Cuiabá - MT. Tese de Doutorado (Faculdade de Filosofia e Ciências Humanas), Universidade de São Paulo, 1994.

OLIVEIRA, A. S. de, SANTOS, F. M. de M., FRANCO, F. M., DURANTE, L. C., CALLEJAS, I. J. A., NOGUEIRA, M. C. de J. A. Estudo da cobertura vegetal arbórea em praças urbanas - Cuiabá/Brasil. In: XI Encontro Nacional de Conforto no Ambiente Construído, 2011, Búzios. Anais... Búzios, 2011. 
PARQUESCOLAR. Programa de Modernização das Escolas do Ensino Secundário. Manual de projecto: arquitectura paisagista. 2009.

RODRIGUES, L. S. \& COPATTI, C. E. Diversidade arbórea das escolas da área urbana de São Vicente do Sul/RS. Biodiversidade Pampeana, Uruguaiana, v. 7, n. 1, p.7-12, 2009.

SEDUC-MT. Secretaria de Estado de Educação. Rede Física. Disponível em: < $\underline{\text { http://www.cuiaba.mt.gov.br/ }}$ upload/arquivo/educacao rede estadual perfil iv.pdf>. Acesso em dez. 2010.

SIMÕES, L. O. C., MAROTTA, H., PIRES, B.B.M., UMBELINO, L. F., COSTA, A.J.S.T. Índices de Arborização em espaço urbano: um estudo de caso no bairro de Vila Isabel, Rio de Janeiro, RJ. Anais do IX ENAU. Brasília, 2001. CD-Room.

WANDELLI, E.V., MARQUES FILHO, A.O. Medidas de radiação solar e índice foliar em coberturas vegetais. Acta Amazônica, v. 29, n. 1, p. 57- 78, 1999. 